\title{
Rapid mapping with remote sensing data during flooding 2005 in Switzerland by object-based methods: a case study
}

\author{
Y. A. Buehler, T. W. Kellenberger, D. Small \& K. I. Itten \\ Remote Sensing Laboratories (RSL)/NPOC, Department of Geography, \\ University of Zurich UZH, Switzerland
}

\begin{abstract}
Rapid mapping and monitoring with remote sensing techniques is an important source of information for decision-makers faced with large scaled disasters. In August 2005 several regions in central Switzerland were affected by severe flooding. The "National Emergency Operations Centre" (NEOC) of Switzerland invoked the International Charter on "Space and Major Disasters", requesting support by remote-sensing data for disaster-management. In this paper, a SPOT-5 and a RADARSAT-1 satellite-scene acquired a few days after the flood-peak are described and processed to map the affected area with object-based methods. The main difficulties with optical images are the small extent of the Swiss landscape, the large height-differences in the relief, shadows, clouds and snow covered areas. Comparing different approaches, it was found that beside the NIR and SWIR band the application of a DEM and a VISNIR water index showed the most promising results for a fast discrimination of the affected areas. The objectbased classification is mainly dependent on threshold-values and Boolean operators. As investigations show, the spatial resolution of the acquired radar dataset in this case is not sufficient to map the affected areas. The results of the classification based on SPOT-5 scenes are up-to-date maps of flooded areas. We show that maps for decision-makers can be produced using auxiliary topographical and land use data. Aerial infrared images acquired from SWISSTOPO after the flooding were used to test the accuracy of the result. Procedures for rapid mapping applications in future disaster cases are discussed. Keywords: rapid mapping, flooding, disaster response, international charter on space and major disasters, natural hazards, object-based classification.
\end{abstract}




\section{Introduction}

Disaster mapping with remote sensing data has been investigated for several years. In the past, the poor availability of appropriate sensors, low temporal resolution, time-consuming data acquisition and distribution, limited image analysis techniques and computer resources - and in addition, the lack of missing awareness about the existence of products limited widespread application Iglseder et al. [1]. Today, major advances reduce these obstructions, enhancing possibilities for a useful disaster-management tool. In general, two types of rapid mapping products are required by end-users: overview-maps of affected areas and damage-maps combined with additional information (e.g. land-use type of flooded area, destroyed traffic routes, changes in flood-levels) Allenbach et al. [2]. This paper focuses on the detection of flooded areas and a raw differentiation of water depth. The creation of overview-information is not required due to the area-wide availability of 1:25'000 topographical maps.

Organisations active in the domain of rapid mapping associated with the International Charter on "Space and Major Disasters" in Europe today are for example UNOSAT in Geneva Switzerland, SERTIT in Strasbourg France and the ZKI at the DLR in Oberpfaffenhofen Germany. The majority of past charter calls concerned areas of a large extent in regions of mainly even topography. Examples are the Elbe-River flooding in autumn 2002 and the destructive Indian Ocean Tsunami in December 2004. In contrast to these disasters types, the flooded areas investigated in this paper are of small spatial extent in the rough topography of the Swiss Alps. An overview of mapping natural hazards in alpine region is provided in Metternich et al. [3].

In August 2005 a $5 b$-cyclone carried large quantities of humid air from the Adriatic Sea to the central Alps. The rainfall that ensued reached intensities above $300 \mathrm{l} / \mathrm{m}^{2}$ over two days, which had never been measured in situ before. Due to a snow line over 3000 meters above sea level and wet conditions in the days before the disaster, the soils were already saturated and could not absorb the additional intense rain Frei [4]. The levels of rivers and lakes rose and flooded farmland, roads and urban areas. The steep terrain of the central Alps caused landslides and mudflows so that many people had to be evacuated. An overview of the main affected regions in Switzerland and the study area is shown in Figure 1. Especially the large extent of affected areas is exceptional for a flood event in Switzerland. Three days after the rainfalls the "National Emergency Operations Centre" (NEOC) invoked the International Charter on "Space and Major Disasters" requesting support by remote-sensing data for disaster-management. The "National Point of Contact" (NPOC) of the "Federal Office of Topography" (SWISSTOPO) as project manager produced rapid mapping products and handed them out to support the decision-makers. Due to the federal organization of the Swiss Civil Protection, several different organisations e.g. cantonal crisis committees, federal offices, the police, fire departments and the army are all possible end-users of rapid mapping products Federal Office for Civil Protection [5]. This paper focuses on the optimisation of rapid mapping products in this particular case. 
To acquire useful satellite-data, a very short timeframe is available in which the affected area is only viewed by a small number of sensors. Additionally, the Swiss Alpine area presents specific challenges to the use of satellite data. The small extent of the landscape requires a high spatial resolution of better than 15 meters, which is only available from a few optical sensors (e.g. SPOT, IKONOS). The large height-differences in the relief cause shadows in optical images and radar-shadow, layover and foreshortening in radar images. In optical images, clouds, cloud-shadow and snow complicate the classification of flooded areas. Due to these difficulties, there are presently only a few datasets available for a rapid classification of the flooded areas in Switzerland.

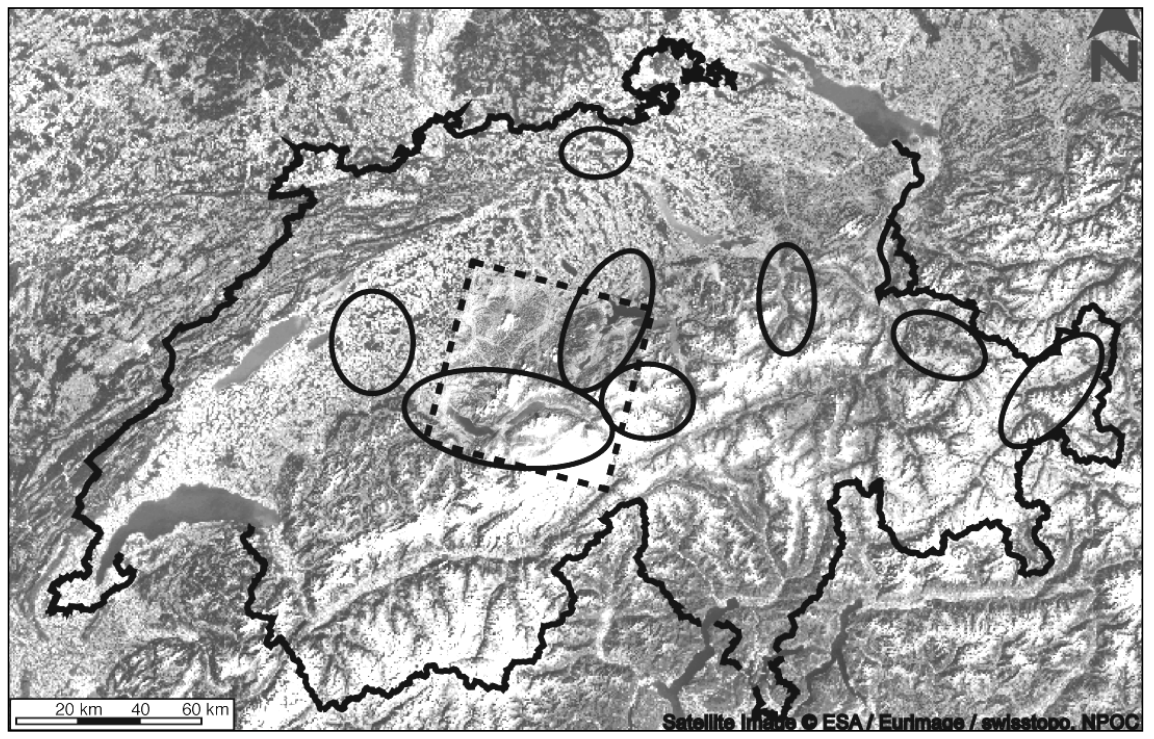

Figure 1: Overview of the main affected areas (ovals) in Switzerland and the study area (dashed rectangle).

\section{Remote sensing data}

\subsection{RADARSAT-1}

The "Canada Centre for Remote Sensing" (CCRS) submitted in response to the Charter invocation a RADARSAT-1 standard mode C-band dataset with a spatial resolution of 28 meters. A small subimage covering the Lake Brienz region is shown in Figure 2. The advantage of radar data compared to optical sensors is its capability to acquire data during the night and through clouds, which is of great advantage for flood monitoring. Investigations with a pre-flood and a post-flood RADARSAT-1 image showed that the spatial resolution is not sufficient to detect small flooded areas of several square meters in the Swiss landscape. The fine mode with a spatial resolution of 9 meters was not acquired but would have been 
a preferable alternative. Further problems such as radar shadow, layover and foreshortening, increased by the rough topography complicate the classification. By the time the Charter was activated and the RADARSAT1 image planed and acquired, much of the flooding had receded, leaving only residual ponds. Additionally, the archive of images acquired with the same geometry for a particular region is small and it is difficult to find pre-disaster scenes for change detection. Further information about geometric and radiometric correction of radar data in mountainous terrain is provided in Small et al. [6]. Due to difficulties mentioned above, the RADARSAT-1 data was not used for the classification of affected areas in this investigation.

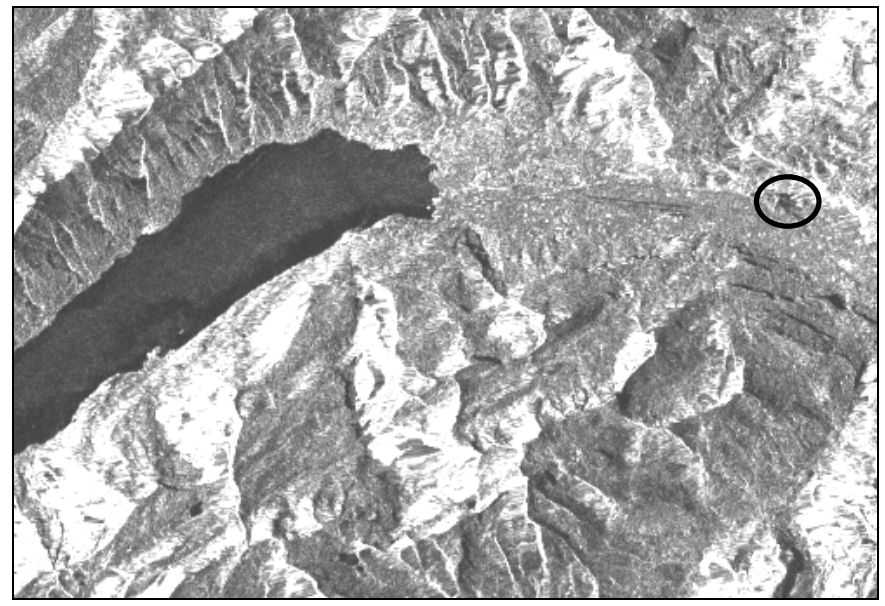

Figure 2: $\quad$ Radarsat-1 geocoded terrain corrected standard mode image in full resolution, acquired on August 28th 2005. The oval highlights a known flooded area.

\subsection{SPOT5}

Spotimage delivered two SpOT5-scenes, acquired on August $26^{\text {th }}$ and $30^{\text {th }} 2005$. As base image for change detection, an image from the data archive acquired on June $12^{\text {th }} 2003$ was applied. SPOT5 carries two sensors HRG providing two panchromatic bands (spatial resolution $5 \mathrm{~m}$ ), two visible bands, a near infrared band (spatial resolution $10 \mathrm{~m}$ ) and a short wave infrared band (spatial resolution $20 \mathrm{~m}$ ). The image swath is $60 \mathrm{~km} \times 60$ to $80 \mathrm{~km}$ depending on the acquisition angle Spotimage [7].

The utility of optical images is highly dependent on characteristics like the revisit time, the repetition rate, the acquisition angle and the scene's cloud-cover Campbell [8]. After the heavy rainfall, clouds obscured more than $80 \%$ of the scene acquired on August $26^{\text {th }} 2005$. By chance, the main parts of the affected valleys were fortunately cloud-free. The scene from August $30^{\text {th }} 2005$ has nearly no cloud-cover but was recorded more than a week after the peak of the floodevent. Figure 3 shows quick-looks of the two post-flood images. 

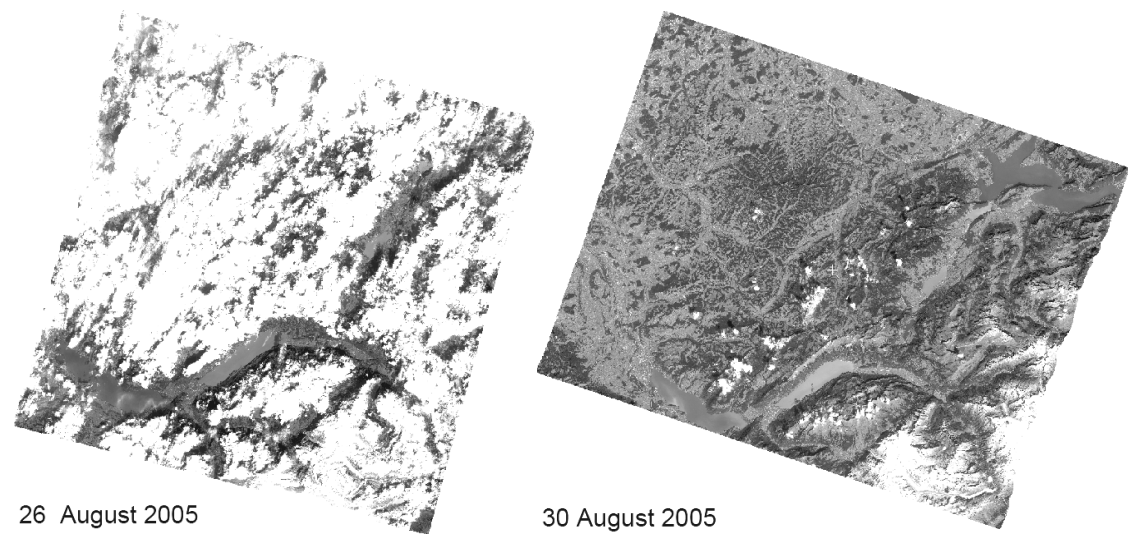

Figure 3: Quicklooks of the Spot5 HRG images acquired after the flooding.

\section{Methodology}

\subsection{Data preprocessing}

Usually the first step in the preprocessing chain for rapid mapping is the geometric calibration. It is the foundation for change detection methods and visualisation by overlaying the images with auxiliary geographical data. The required accuracy lies below the extent of one pixel (SPOT5 $10 \mathrm{~m}$, RADARSAT1 $28 \mathrm{~m}$ ). The rough terrain of the Swiss Alps makes accurate geometric calibration both more important and more difficult. Use of a digital elevation model (DEM) improves the accuracy remarkably Meier [9], Kellenberger [10].

Correction of atmospheric and illumination effects is not always possible within the fast preprocessing required in rapid mapping. Due to the inhomogeneity within a single scene, the lack of atmospheric parameters and time consuming processing, these corrections were not conducted in this investigation. To normalize the datasets, the pixel values are transformed from digital numbers to physical units (at sensor radiance) applying the calibration coefficients in equation (1) Schowengerdt [11].

$$
L s=C_{0}+C_{1} * D N
$$

$L s=$ at sensor radiance

$C_{0}=$ calibration offset or bias

$C_{1}=$ calibration gain

$D N=$ digital numbers

\subsection{Segmentation}

Traditionally, classification of remote sensing data has been conducted using a pixel-based approach, where the spectral response of one pixel and possibly its very close surroundings is used for classification. Object oriented approaches 
first merge adjacent pixels of high homogeneity in spectral reflectance or shape to image objects, dependent on a chosen scale factor. Classification on the basis of image-polygons allows use of the spectral statistics in addition to the integration of intrinsic, topological and contextual information. Furthermore, the approach improves the possibilities to include knowledge from sources other than remote sensing data Benz et al. [12]. A disadvantage in the field of rapid mapping is the large amount of required processing power and memory, slowing down the segmentation and classification process.

The aim of segmentation is to create image objects that accurately represent the shapes and sizes of the water-covered areas in the Sрот5 pre-disaster and post-disaster scenes. Investigations showed that best results are achieved based on a VISNIR water index (2), the near infrared band NIR and the Swiss digital elevation model DHM25 on a low scale. According to the normalized difference vegetation index NDVI Campbell [8], the VISNIR water index is based on the band containing high spectral response (green) and the band that contains low spectral response (NIR) for water. Figure 4 shows part of the calculated water index band from the pre-disaster scene superimposed with the computed segments.

$$
\text { VISNIR water index }=\frac{\text { green }-N I R}{\text { green }+ \text { NIR }}
$$

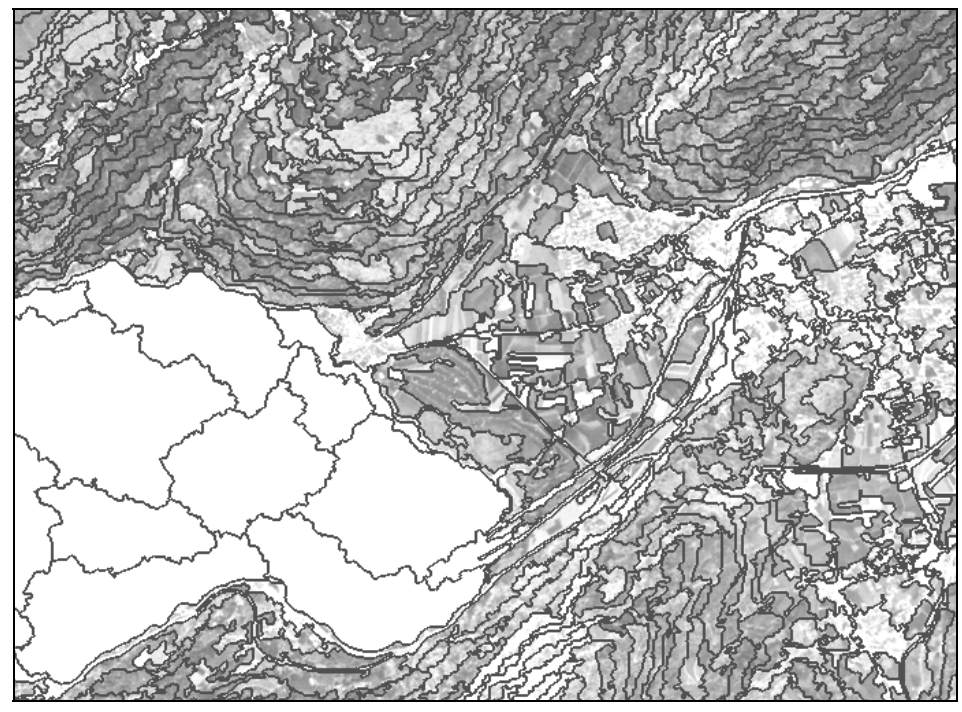

Figure 4: Computed water index of the pre-disaster scene superimposed with the generated image-objects.

\subsection{Classification}

Based on the computed segments, the first classification is performed on the predisaster scene. The aim is to generate a precise representation of the areas 
covered by water before the flood. The classification is based mainly on the VISNIR water index (2), the NIR band and the standard deviation of the height of the pixels merged in one polygon, which is an estimate of the flatness of a segment.

The second classification, performed in the post-disaster scene, highlights the areas that are covered by water now but were not in the pre-disaster scene. The detection of flooded areas is based on the water index (1), the SWIR band, the NIR band, the standard deviation of the height of the pixels merged in one polygon and Boolean combinations. In addition to the flooded areas, clouds, shadow and snow are separated to avoid intersections with the flood classes.

To save time, the classes are defined by thresholds and not by samples. An advantage of this method is that later images from the same sensor can be classified with the same or slightly modified class definitions. The dataset from August $30^{\text {th }} 2005$ (Figure 3) was acquired under different atmospheric conditions and has a larger offnadir view angle, leading to differences in the measured spectral response. A classification with the same class definitions applied in the first post-disaster scene shows accurate results for flooded areas. This approach allows an uncomplicated monitoring of the affected areas, and production of dynamic flood maps. The same approach could be applied during future flood events, helping to speed up the production of rapid mapping products. More research has to be done to check the potential for adapting the established class definitions to further scenes from the same or different sensors.

To control the achieved accuracy of the object-based classification, infrared aerial images flown on August $29^{\text {th }} 2005$ by SWISSTOPO were used. The scanned aerial infrared images have an average scale of 1:10'000 and have been resampled to a pixel size of $0.25 \mathrm{~m}$ to accomplish the accuracy assessment. Flooded areas of different water levels are perfectly identifiable on these images, which makes them the best groundtruth available to assess the accuracy of the classification from the SPOT5 scene. Table 1 shows the results of this evaluation.

Table 1: $\quad$ Accuracy assessment for the two flood classes.

\begin{tabular}{lcc}
\hline & Flooded area low water level & Flooded area high water level \\
$\begin{array}{l}\text { Producer's } \\
\text { accuracy }\end{array}$ & 0.907 & 0.929 \\
$\begin{array}{l}\text { User's accuracy } \\
\text { Kappa Index per } \\
\text { class }\end{array}$ & 0.985 & 0.995 \\
\hline $\begin{array}{l}\text { Overall accuracy } \\
\text { Kappa overall }\end{array}$ & 0.864 & 0.816 \\
\hline
\end{tabular}

Especially the high Kappa coefficient value of 0.839 verifies the good results of the classification that a visual evaluation promises. Minor misclassifications are mainly caused by the time difference between the acquire dates of the satellite scene and the aerial images. Additionally, flooded areas of a very small extent or with a very high fraction of debris cannot be detected in the Spot5 image. 


\section{Results}

Rapid mapping products aim to be quickly available and easy to read for end users. The polygons classified as flooded are combined with topographical maps to generate a layout that the decision makers are familiar with, and allow them to add further information. This procedure enables extraction of information about the type of affected area (e.g. affected traffic routes or flooded settlements). Figure 5 shows an example of a topographical map with flooded areas superimposed, as detected within the SPOT5 post-disaster image.

To produce overview maps on a larger scale, the flood-polygons could be plotted over the original satellite data or over satellite data combined with topographical maps. These products can be valuable tools when planning rescue efforts shortly after the disaster.

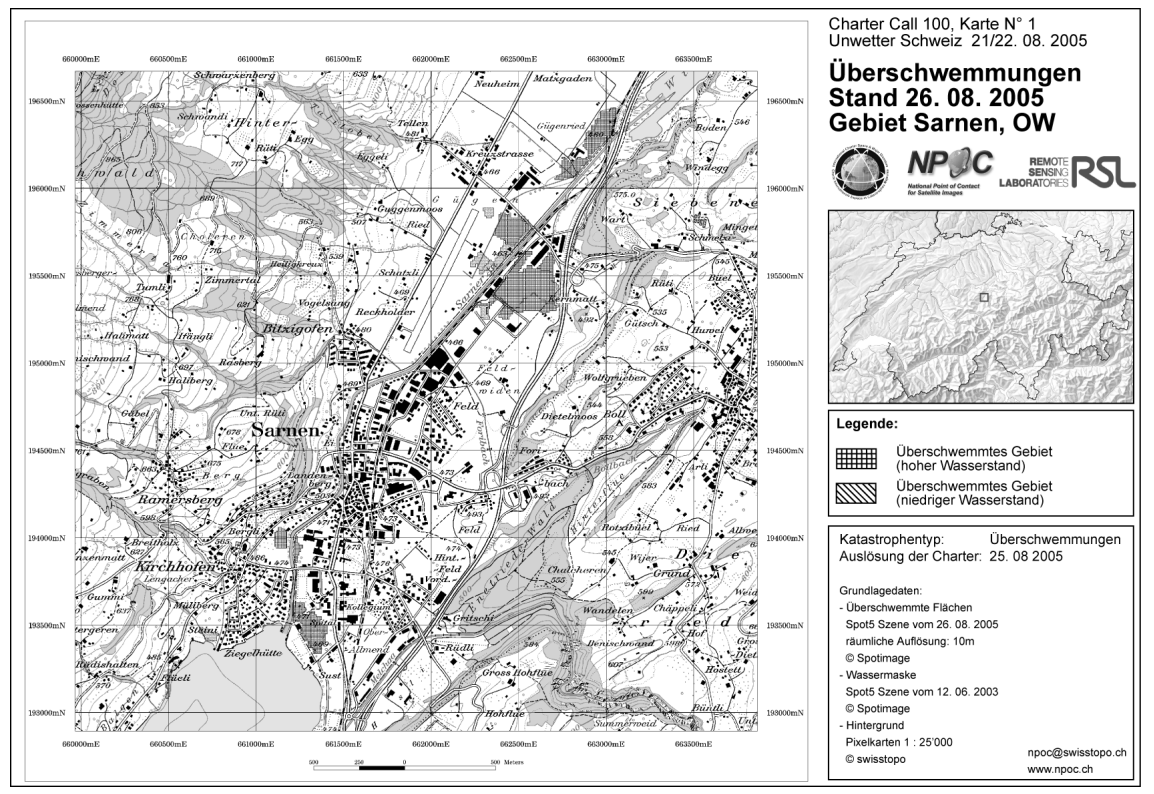

Figure 5: Rapid mapping product to support the disaster management, topographical map CSWISSTOPO (BD053189).

\section{Conclusions}

The results from this investigation show that object-based classification of remotely sensed data can produce valuable base data for rapid mapping products, supporting decision makers in time of crisis. An estimation of the time required for the production steps after the arrival of the remotely sensed raw data is given in Table 2. The extracted objects representing the flooded areas can be exported to a GIS and intersected with land-use or population density maps to estimate 
economic damage and other valuable information. These possibilities can provide an important support for disaster management.

Table 2: $\quad$ Estimation of the time needed for the main steps of rapid mapping (for a single scene).

\begin{tabular}{l|l|l}
\hline Basic work & $\begin{array}{l}\text { Geometric calibration: } \\
\text { Segmentation }\end{array}$ & $\begin{array}{l}\text { ca. } 1 \mathrm{~h} \\
\text { ca. } 1 \mathrm{~h}\end{array}$ \\
& $\begin{array}{l}\text { Adaptation of the classification for } \\
\text { the pre-disaster scene }\end{array}$ & ca. $1 \mathrm{~h}$ \\
& $\begin{array}{l}\text { Adaptation of the classification for } \\
\text { the post-disaster scene: }\end{array}$ & ca. $1 \mathrm{~h}$ \\
& $\begin{array}{l}\text { Validation of the classification } \\
\text { result: }\end{array}$ & ca. $1 \mathrm{~h}$ \\
\hline Map production & Map generation: & ca. $1 / 2 \mathrm{~h} \mathrm{per} \mathrm{map}$ \\
& Map layout: & ca. $1 / 2 \mathrm{~h} \mathrm{per} \mathrm{map}$ \\
\hline Total & & ca. $6 \mathrm{~h}$ \\
\hline
\end{tabular}

The temporal availability of high spatial resolution satellite data has improved within the last decade and this trend is still going on. The "International Charter on Space and Major Disasters" provides the infrastructure to acquire the appropriate data a short time after a disaster and enables the support with rapid mapping products. To improve the international success of this institution it is important that the regions, which are affected by a disaster, invoke the charter immediately after the event and that more satellite operators join the charter to raise the probability of image availability.

To enable the detection of small flooded areas in rough terrain, the spatial resolution ought to be better than 15 meters. The acquisition date should be as close as possible to the disaster event so that most of the affected areas are still covered by water.

Common cloud cover in the time after flood-events triggered by heavy rainfall is the main problem in rapid-detecting affected areas in optical satellite data. The spectral appearance of urban areas under cloud shadow is very similar to the appearance of water in SРOT5 data and reduces the accuracy of the classification. In a further step of research a fast automatic extraction of clouds and shadow should be developed to improve the speed and quality of the classification. Application of radar data can bypass the problems of clouds and cloud shadow, but is limited by layover, foreshortening and radar-shadow in mountainous areas. Although these limitations exist, there is a need for research on object-based classification in rapid mapping with combined data from radar and optical sensors.

\section{Acknowledgements}

The authors like to thank swisstopo for data-support and the geometric calibration, Spotimage and the Canadian Space Agency for the satellite data. 


\section{References}

[1] Iglseder, H., Arensfischer, W., Wolfensberger, W., Small Satellite Constellations for Disaster Detection and Monitoring, Natural Hazards, volume 15, issue 11, pp. 79-85, 1995

[2] Allenbach, B. et al., Rapid EO Disaster Mapping Service: Added value, feedback and perspectives after 4 years of Charter actions, SERTIT, 2005

[3] Metternich, G., Hurni, L. \& Gogu, R., Remote Sensing of landslides: An analysis of the potential contribution to geo-spatial systems for hazard assessment in mountainous environments, Remote Sensing of Environment, volume 98, issues 2-3, pp. 284-303, 15 October 2005

[4] Frei, C., August-Hochwasser 2005: Analyse der Niederschlagsverteilung, Bundesamt für Meteorologie und Klimatologie (MeteoSchweiz), 2005

[5] Federal Office for Civil Protection (Bundesamt für Bevölkerungsschutz,) http://www.bevoelkerungsschutz.admin.ch (access December 12th 2005)

[6] Small, D. Meier, E. Nüesch, D., Robust Radiometric Terrain Correction for SAR Image Comparison, Geoscience and Remote Sensing Symposium IGARSS '04. Proceedings, IEEE International, volume 3, pp. 1730 - 1733, 2004

[7] Spotimage, http://www.spotimage.fr (access December 12th 2005)

[8] Campbell, J. B., Introduction to Remote Sensing third edition, Taylor \& Francis London, pp. 272-285, 465-467, 2002

[9] Meier, E., Geometrische Korrektur von Bildern orbitgestützter SARSysteme, Remote Sensing Series volume 15, 1989

[10] Kellenberger, T. W., Erfassung der Waldflächen in der Schweiz mit multispektralen Satellitenbilddaten, PhD Thesis, RSL Department of Geography, UZH University of Zurich, pp. 142-164, 1996

[11] Schowengerdt, R. A., Remote Sensing - models and methods for image processing, Academic Press, San Diego, pp. 311-313, 1997

[12] Benz, U. et al., Multi-resolution, object-oriented fuzzy analysis of remote sensing data for GIS-ready information, ISPRS Journal of Photogrammetry \& Remote Sensing volume 58, pp. 239 - 258, 2004 